\title{
Pengaruh Jarak Tanam Terhadap Pertumbuhan Dan Hasil Tanaman Sawi Pak Choi (Brassica rapa)
}

\author{
Emilia S.A. Wangge ${ }^{1}$, Imanuel Sedi Benu \\ Emilia_wangge@yahoo.co.id
}

\begin{abstract}
ABSTRAK
This study aims at determining the impact of planting distanceon the growth and yield of Pak Choyand determining the optimal distance that can optimize the growth and yield of Pak Choi.

This study employed group random design with 6 treatments of planting distance, namelyJ1 $=20 \mathrm{~cm} \times 25 \mathrm{~cm}, \mathrm{~J} 2=20 \mathrm{~cm} \times 20 \mathrm{~cm}, \mathrm{~J} 3=$ Planting distance $20 \mathrm{~cm} \times 15 \mathrm{~cm}, \mathrm{~J} 4=$ Planting distance $20 \mathrm{~cm} \times 10 \mathrm{~cm}, \mathrm{~J} 5=10 \mathrm{~cm} \times 15 \mathrm{~cm}, \mathrm{~J} 6=10 \mathrm{~cm} \times 10 \mathrm{~cm}$. Each treatment was repeated 4 times, so that there were 24 specimen garden-beds.

It is found out that planting distance did not have any impact on plant height, the width of leaves, and numbers of leaves at age of 10-20 days after planting, whereas there was an impact on plant age of 25-35 days after planting on plant height of $15.59 \mathrm{~cm}$, number of leaves of 9.17 $\mathrm{cm}$, width of leaves of $52.28 \mathrm{cmand}$ fresh Pak Choy weightof $148.4 \mathrm{~g}$ per plant, fresh weight per ha 1204.43 ha.
\end{abstract}

Keywords: planting distance, the growth and yield, Pak Choi Plants

PENDAHULUAN

Sawi Pak Choi (Bransica rapa)

merupakan tanaman sayuran yang ada di

Indonesia. Haryanto (2003) mengemukakan

Pak Choi dan Caisin adalah satu genus

hanya spesiesnya yang berbeda. Penampilan

Pak Choi amat mirip dengan Caisin tetapi

Pak Choi lebih pendek dan kompak, tangkai

daunnya lebih tebal dari Caisin dan berdaun

halus (tidak berbulu).
Data Produksi sawi Pak Choi di Indonesia tahun 2011, dengan luas panen 56,414 ha dan mempunyai produksi 562,838 ton dengan produktifitas 9,989 ton/ha. Sedangkan produksi tahun 2012 dengan luas panen 59,450 ha dan mempunyai produksi 583,770 ton, dengan produktifitas 9,19 ton/ha (Sumber Direktorat Jendral Hortikultura Depertemen Pertanian, 2012 ). Sedangkan produksi sawi Pak Choi di Kabupaten Ende tahun 2011, dengan luas 


\section{Emilia: Pengaruh Jarak Tanam Terhadap Pertumbuhan Dan Hasil TanamanSawi Pak Choi (Brassica rapa)}

panen 23,5 ha dan mempunyai tingkat produksi mencapai 40,6 ton dengan produktifitas 1,56 ton/ha. Dan tahun 2012 dengan luas panen 24,5 ha dan mempunyai tingkat produksi mencapai 41,5 ton deengan produktifitas 1,55 ton/ha (Dinas Pertanian Kabupaten Ende). Berdasarkan data tersebut diatas produktifitas tanaman sawi pakchoi untuk Kabupaten Ende masih sangat rendah, dibandingkan dengan produksi sawi Nasional. Kondisi ini disebabkan karena jarak tanam yang belum optimal dan sistim pemupukan belum begitu tepat dengan takaran sebenarnya. Dinas Kabupaten Ende mengemukakan jarak tanam yang sering digunakan Petani di Kabupaten Ende menggunakan jarak tanam $10 \mathrm{~cm} \times 10 \mathrm{~cm}$ dan $10 \mathrm{~cm} \times 15 \mathrm{~cm}$ dengan ukuran bedeng panjang $100 \mathrm{~cm}$. Sehubungan dengan hal tersebut perlu di lakukan jarak tanam pada tanaman sawi Pak Choi, guna meningkatkan produksi hasil sawi Pak Choi.
Pengaturan jarak tanam dengan manipulasi jarak antara dalam barisan menentukan populasi suatu pertanaman, dengan pengaturan jarak tanam populasi tanaman sampai batas tertentu, tanaman dapat memanfaatkan lingkungan tumbuhan secara efisien. Pengaturan jarak tanam dan kerapatan populasi memegang peranan penting sehingga tanaman dapat memanfatkan radiasi surya supaya lebih efisien (Junita,2006).

Penggunaan jarak tanam pada dasarnya untuk memberikan ruangan sekitar pertumbuhan tanaman yang baik tanpa mengalami persaingan antara sesama tanaman. (Haryanto. 2001 ). Pada akhirnya, penampilan masing-masing tanaman secara individu menurun karena persaingan untuk cahaya dan factor pertumbuhan yang lain. Tanaman memberikan respon dengan mengurangi ukuran baik pada seluruh tanaman maupun pada bagian-bagian tertentu. (Hidayah, 2007). Jarak tanam untuk 
Emilia: Pengaruh Jarak Tanam Terhadap Pertumbuhan Dan Hasil TanamanSawi Pak Choi (Brassica rapa)

jenis sawi pak choi dapat menggunakan jarak tanam $20 \mathrm{~cm} \times 15 \mathrm{~cm}, 20 \mathrm{~cm} \times 20 \mathrm{~cm}$, hingga $20 \mathrm{~cm} \times 25 \mathrm{~cm}$.

Hasil penelitian Purwati , (2011), sawi Pak Choy dapat di tanam pada bedengan dengan ukuran lebar $100 \mathrm{~cm}-200 \mathrm{~cm}$ dan panjang sesuai dengan ukuran petak tanah, dengan jarak tanam $20 \mathrm{~cm} \times 20 \mathrm{~cm}$ menghasilkan 4-5,6 ton tha atau meningkatkan hasil produktifitas dan kualitas hasil ( kenaikan hasil 25\%). Tinggi bedeng yang digunakan $30 \mathrm{~cm}$ jarak antara bedeng $30 \mathrm{~cm}$, hal ini dimaksudkan digunakan saluran drainase. Jarak tanam sangat erat kaitannya dengan jumlah yang dihasilkannya, Karena itu pengaturan jarak tanam perlu diperhatikan untuk memenuhi sasaran agronomi yaitu produksi maksimal.

Selama ini ditingkat petani di Indonesia pengaturan jarak tanam sawi biasanya tanpa perhitungan secara khusus hanya berdasarkan kebiasaan tanpa mengetahui jarak tanam yang tepat untuk penanaman tanaman sawi Pak Choi. Berdasarkan uraian di atas maka penulis perlu melakukan penelitian dengan judul. "Pengaruh Jarak Tanam Terhadap Pertumbuhan Dan Hasil Sawi Pak Choi” (Brassica rapa)

\section{METODE PENELITIAN}

\section{Waktu dan Tempat}

Penelitian ini dilaksanakan di Kebun Pertanian di kelurahan Rewarangga Kecamatan Ende Timur Kabupaten Ende yang mempunyai ketinggian tempat 400-600 mdpl, suhu $20^{0}-25^{0}$. dengan curah hujan 1000-1500 milimeter pertahun, (Badan Statistik Kab.Ende 2010). Penelitian dilaksanakan selama 3 bulan., mulai Juli sampai dengan September 2013

\section{Bahan dan Alat}

Bahan yang digunakan dalam penelitian ini adalah benih tanaman sawi Pak Coi dengan varietas caisim. Peralatan yang digunakan yaitu, cangkul, parang, pisau, 


\section{Emilia: Pengaruh Jarak Tanam Terhadap Pertumbuhan Dan Hasil TanamanSawi Pak Choi (Brassica rapa)}

ember, penggaruk, pupuk kandang ayam , timbangan, mistar, dan alat tulis.

\section{Rancangan Penelitian}

Penelitian disusun berdasarkan Rancangan Acak kelompok (RAK) yang dengan 6 perlakuan diulang sebanyak 4 kali. Faktor yang diamati adalah, Faktor jarak tanam (J) yang terdiri atas 4 taraf, yaitu : J1 $=$ jarak tanam $10 \mathrm{~cm} \times 10 \mathrm{~cm}, \mathrm{~J} 2=$ jarak tanam $10 \mathrm{~cm} \times 15 \mathrm{~cm}, J 3=$ jarak tanam $20 \mathrm{~cm} \times 10 \mathrm{~cm}, \mathrm{~J} 4=$ jarak tanam $20 \mathrm{~cm} \times$ $15 \mathrm{~cm}, \mathrm{~J} 5=$ jarak tanam $20 \mathrm{~cm} \times 20 \mathrm{~cm}$ dan $\mathrm{J} 6=$ jarak tanam $20 \mathrm{~cm} \times 25 \mathrm{~cm}$.

\section{Variabel Pengamatan}

Pengamatan dilakukan pada variable pertumbuhan, hasil, dan sifat fisik tanah. Pengamatan terhadap variabel pertumbuhan dan hasil di lakukan lima rumpun tanaman sampel pada masing-masing petak

Variabel pertumbuhan (Tinggi tanam, Luas daun, dan Jumlah daun) dan variabel hasil (Bobot Segar Sawi Per Tanaman dan Berat segar sawi per hektar).

\author{
Analisis Data \\ Data yang dikumpulkan dianalisis \\ secara statistik dengan menggunakan \\ analisis varians sesuai dengan rancangan \\ yang digunakan. Apabila perlakuan
} menunjukan pengaruh nyata terhadap variable yang diamati, maka dilanjutkan dengan uji BNT taraf $5 \%$ (Gomez dan Gomes, 2007).

\section{HASIL DAN PEMBAHASAN}

Hasil analisis statistik menunjukan bahwa penggunaan jarak tanam pada tanaman sawi pak choi tidak berpengaruh nyata pada tinggi tanaman, jumlah daun dan luas daun, umur 10, 15 dan 20 hari setelah tanam, dan pengaruh sangat nyata pada umur 25, 30 dan 35 hari setelah tanam, berat segar $\tan ^{-1}$, dan berat segar ha- ${ }^{-1}$.

\section{Variabel Pertumbuhan}

Hasil analisis statistik menunjukan bahwa penggunaan jarak tanam tidak berpengaruh nyata pada tinggi tanaman, jumlah daun dan luas daun, umur 10, 15 dan 
Emilia: Pengaruh Jarak Tanam Terhadap Pertumbuhan Dan Hasil TanamanSawi Pak Choi (Brassica rapa)

20 hari setelah tanam, dan pengaruh sangat tanam, (tabel 4.2).

nyata pada umur 25,30 dan 35 hari setelah

Tabel 4.2 Pengaruh Jarak Tanam Terhadap Tinggi Tanaman, Jumlah Daun, dan Luas Daun.

\begin{tabular}{|c|c|c|c|c|c|c|}
\hline \multirow{2}{*}{ Perlakuan } & \multicolumn{6}{|c|}{ Tinggi Tanaman $(\mathrm{cm})$} \\
\hline & $10 \mathrm{hst}$ & $15 \mathrm{hst}$ & $20 \mathrm{hst}$ & $25 \mathrm{hst}$ & $30 \mathrm{hst}$ & $35 \mathrm{hst}$ \\
\hline $\mathrm{J} 1$ & $6.58 \mathrm{a}$ & $9.48 \mathrm{a}$ & $12.78 \mathrm{a}$ & $16.93 \mathrm{a}$ & $20.98 a b$ & $25.03 \mathrm{ab}$ \\
\hline $\mathrm{J} 2$ & $6.85 \mathrm{a}$ & $9.68 \mathrm{a}$ & $13.45 \mathrm{a}$ & $17.03 \mathrm{a}$ & $21.28 \mathrm{a}$ & $25.28 \mathrm{a}$ \\
\hline $\mathrm{J} 3$ & $5.53 \mathrm{a}$ & $8.90 \mathrm{a}$ & $12.63 \mathrm{a}$ & $16.33 \mathrm{c}$ & $19.28 \mathrm{c}$ & $23.13 \mathrm{c}$ \\
\hline $\mathrm{J} 4$ & $5.75 \mathrm{a}$ & $9.00 \mathrm{a}$ & $12.18 \mathrm{a}$ & $15.75 \mathrm{~d}$ & $19.05 \mathrm{~cd}$ & $22.65 \mathrm{~cd}$ \\
\hline $\mathrm{J} 5$ & $5.95 \mathrm{a}$ & $9.08 \mathrm{a}$ & $11.88 \mathrm{a}$ & $15.45 \mathrm{e}$ & $18.70 \mathrm{~d}$ & $22.10 \mathrm{~d}$ \\
\hline $\mathrm{J} 6$ & $6.13 \mathrm{a}$ & $9.30 \mathrm{a}$ & $11.93 \mathrm{a}$ & $15.08 \mathrm{f}$ & $18.25 \mathrm{e}$ & $21.43 \mathrm{e}$ \\
\hline BNT 5\% & TN & TN & TN & 0.29 & 0.39 & 0.55 \\
\hline \multirow{2}{*}{ Perlakuan } & \multicolumn{6}{|c|}{ Jumlah Daun $(\mathrm{cm})$} \\
\hline & $10 \mathrm{hst}$ & $15 \mathrm{hst}$ & $20 \mathrm{hst}$ & $25 \mathrm{hst}$ & $30 \mathrm{hst}$ & 35 hst \\
\hline $\mathrm{J} 1$ & $4.75 \mathrm{a}$ & $6.25 \mathrm{a}$ & $7.50 \mathrm{a}$ & $9.25 \mathrm{ab}$ & $11.50 \mathrm{ab}$ & $13.25 \mathrm{~b}$ \\
\hline $\mathrm{J} 2$ & $5.25 \mathrm{a}$ & $6.00 \mathrm{a}$ & $8.00 \mathrm{a}$ & $9.75 \mathrm{a}$ & $12.00 \mathrm{a}$ & $14.00 \mathrm{a}$ \\
\hline $\mathrm{J} 3$ & $4.25 \mathrm{a}$ & $5.75 \mathrm{a}$ & $7.25 \mathrm{a}$ & $9.00 \mathrm{~b}$ & $11.00 \mathrm{~b}$ & $13.00 \mathrm{bc}$ \\
\hline $\mathrm{J} 4$ & $4.50 \mathrm{a}$ & $5.75 \mathrm{a}$ & $7.00 \mathrm{a}$ & $8.00 \mathrm{~cd}$ & $9.75 \mathrm{~cd}$ & $11.75 \mathrm{~cd}$ \\
\hline J5 & $4.25 \mathrm{a}$ & $5.75 \mathrm{a}$ & $6.50 \mathrm{a}$ & $7.50 \mathrm{~d}$ & $9.25 \mathrm{de}$ & $11.25 \mathrm{de}$ \\
\hline J6 & $4.25 \mathrm{a}$ & $5.25 \mathrm{a}$ & $6.00 \mathrm{a}$ & $6.75 \mathrm{e}$ & $8.75 \mathrm{e}$ & $11.00 \mathrm{e}$ \\
\hline BNT 5\% & $\mathrm{TN}$ & $\mathrm{TN}$ & $\mathrm{TN}$ & 0.72 & 0.79 & 0.69 \\
\hline \multirow{2}{*}{ Perlakuan } & \multicolumn{6}{|c|}{ Luas Daun $(\mathrm{cm})$} \\
\hline & $10 \mathrm{hst}$ & $15 \mathrm{hst}$ & $20 \mathrm{hst}$ & $25 \mathrm{hst}$ & $30 \mathrm{hst}$ & $35 \mathrm{hst}$ \\
\hline J1 & $13.24 \mathrm{a}$ & $21.71 \mathrm{a}$ & $33.72 \mathrm{a}$ & $56.78 \mathrm{ab}$ & $78.74 \mathrm{ab}$ & $89.17 \mathrm{bc}$ \\
\hline $\mathrm{J} 2$ & $14.30 \mathrm{a}$ & $23.01 \mathrm{a}$ & $33.93 \mathrm{a}$ & $59.84 \mathrm{a}$ & $82.68 \mathrm{a}$ & $93.97 \mathrm{a}$ \\
\hline $\mathrm{J} 3$ & $13.53 \mathrm{a}$ & $22.55 \mathrm{a}$ & $32.68 \mathrm{a}$ & $53.63 \mathrm{bc}$ & $74.05 \mathrm{bc}$ & $87.70 \mathrm{~cd}$ \\
\hline $\mathrm{J} 4$ & $13.65 \mathrm{a}$ & $22.83 \mathrm{a}$ & $30.56 \mathrm{a}$ & $42.61 \mathrm{de}$ & $63.01 \mathrm{de}$ & $77.27 \mathrm{ef}$ \\
\hline J5 & $13.17 \mathrm{a}$ & $22.13 \mathrm{a}$ & $23.75 \mathrm{a}$ & $35.79 \mathrm{e}$ & $57.59 \mathrm{ef}$ & $76.35 \mathrm{fg}$ \\
\hline J6 & $12.95 \mathrm{a}$ & $22.93 \mathrm{a}$ & $19.15 \mathrm{a}$ & $26.72 \mathrm{f}$ & $51.86 \mathrm{f}$ & $73.83 \mathrm{~g}$ \\
\hline BNT 5\% & $\mathrm{TN}$ & $\mathrm{TN}$ & $\mathrm{TN}$ & 7.51 & 7.43 & 3.10 \\
\hline
\end{tabular}

Keterangan : angka - angka yang diikuti oleh huruf yang sama pada kolom yang sama berarti tidak beda nyata sama pada taraf uji BNT $5 \%$.

Pada umur 10 - 20 hari setelah tanam menunjukan bahwa perbedaan jarak tanam tidak berpengaruh nyata pada tinggi tanaman, jumlah daun, dan luas pada 


\section{Emilia: Pengaruh Jarak Tanam Terhadap Pertumbuhan Dan Hasil TanamanSawi Pak Choi (Brassica rapa)}

tanaman sawi pak choi. Hal ini dikarenakan bahwa pada umur tanam tersebut, tanaman masih relatif kecil dan belum terjadi kompetisi antara tanaman. (Anom, 2013 ). Perlakuan perbedaan jarak tanam pada tanama sawi pak choi pada umur $25-35$ hari setelah tanam dapat meningkatkan tinggi tanaman, jumlah daun dan luas daun, dimana semakin besar jarak tanam untuk setiap perlakuan (J6，J5，J4，J3，J1，J2) memberikan peningkatan persentase. Pada variabel tinggi tanaman dengan jarak tanam dari $10 \times 10 \mathrm{~cm}$ ke $10 \times 15 \mathrm{~cm}$ dapat meningkatkan tinggi tanaman sebesar 1,23 $\%, 20 \times 10 \mathrm{~cm}$ meningkat sebesar $1.63 \%$, $20 \times 15 \mathrm{~cm}$ meningkat sebesar $1,26 \%, 20 \times$ $25 \mathrm{~cm}$ meningkat sebesar $6,67 \%, 20 \times 20$ cm meningkat sebesar $1,92 \%$, dari $10 \times 10$ $\mathrm{cm}$ ke 20 x $20 \mathrm{~cm}$ meningkat sebesar 14.17 $\%$. Pada variabel jumlah daun, dengan jarak tanam dari $10 \times 10 \mathrm{~cm}$ ke $10 \times 15 \mathrm{~cm}$ dapat meningkatkan jumlah daun sebesar 4,50\%, $20 \times 10 \mathrm{~cm}$ meningkat sebesar 4,43\%, $20 \times$
$15 \mathrm{~cm}$ meningkat sebesar $8,36 \%, 20 \times 25$ cm meningkat sebesar $4,34 \%, 20 \times 20 \mathrm{~cm}$ meningkat sebesar $4,58 \%$, dari $10 \times 10 \mathrm{~cm}$ ke $20 \times 20 \mathrm{~cm}$ meningkat sebesar $23.66 \%$. Pada variabel luas daun, dengan jarak tanam dari $10 \times 10 \mathrm{~cm}$ ke $10 \times 15 \mathrm{~cm}$ dapat meningkatkan luas daun sebesar 9,31\%, 20 x $10 \mathrm{~cm}$ meningkat sebesar $8,48 \%, 20$ x 15 $\mathrm{cm}$ meningkat sebesar 12, $06 \%, 20 \times 25 \mathrm{~cm}$ meningkat sebesar $3,13 \%, 20 \times 20 \mathrm{~cm}$ meningkat sebesar $6,48 \%$, dari $10 \times 10 \mathrm{~cm}$ ke 20 x $20 \mathrm{~cm}$ meningkat sebesar 33.88 . Meningkatnya persentase tinggi tanaman, jumlah daun dan luas daun, ini menunjukan bahwa semakin besarnya jarak tanam yang dilakukan, semakin meningkatkan pertumbuhan tinggi tanaman, jumlah daun dan luas daun pada tanaman sawi pak choi. Dengan adanya sistim penggunaan jarak tanam yang baik pada tanaman sawi pak choi akan memberikan pertumbuhan tanaman sawi pak choi yang optimal. Penggunaan jarak tanam yang baik dapat 


\section{Emilia: Pengaruh Jarak Tanam Terhadap Pertumbuhan Dan Hasil TanamanSawi Pak Choi (Brassica rapa)}

memperkecil ruang tumbuhnya gulma dan juga mengurangi kompetisi antara tanaman. Kurangnya kompetisi antara tanaman dengan gulma akan memberikan suatu keuntungan bagi setiap individu tanaman sawi pak Choi karena dapat menyerap unsur hara lebih optimal dan akan memberikan hasil yang optimal pula, (Rieuwpassa J Alexander, 2011).

Penggunaan jarak tanam yang sesuai akan memberikan pencayaan yang baik sehingga proses fotosintesis akan belangsung dengan baik dan memberikan kestabilan tumbuhnya tanaman sawi pak choi. (Anom, 2012). Dari hasil penelitian diperoleh, penggunaan jarak tanam pada tanaman sawi pak choy yang di tanam pada bedengan dengan ukuran lebar $100 \mathrm{~cm}-200$ $\mathrm{cm}$ dan panjang sesuai dengan ukuran petak tanah, dengan jarak tanam $20 \mathrm{~cm} \times 20 \mathrm{~cm}$ menghasilkan 45-55 ton/ha atau meningkatkan hasil produktifitas dan kualitas hasil sebesar $25 \%$ (Anonim, 2011).
Penggunaan jarak tanam $10 \times 10 \mathrm{~cm}$ (J6) memberikan tinggi tanaman, jumlah daun, dan luas daun pada umur 25 - 35 hari setelah tanam yang paling rendah dibanding yang lainnya. Hal ini disebabkan karena penggunaan jarak tanam $10 \mathrm{~cm} \times 10 \mathrm{~cm}$ relatif terlalu rapat sehingga timbulnya kompetisi antara tanaman yang satu dengan lainnya, sehingga kemampuan tanaman untuk menyerap unsur hara kurang maksimal. Semakin rapat jarak tanam maka akan mengurangi intensitas proses fotosintesis dikarenakan tanaman saling ternaungi ( Anom, 2011 ). Dan penggunaan jarak tanam $20 \times 20 \mathrm{~cm}$ (J2) memberikan hasil yang paling tinggi dari pelakuan lainnya dengan peningkatan tinggi tanaman $14,17 \%$, dan jumlah daun $23,66 \%$ dan luas daun $33,88 \%$, ini menunjukan bahwa semakin lebar jarak tanam yang digunakan akan mengurangi kompetisi antara tanaman dalam hal kemampuan menyerap unsur hara dan proses pencahayaan diterima pada setiap 


\section{Emilia: Pengaruh Jarak Tanam Terhadap Pertumbuhan Dan Hasil TanamanSawi Pak Choi (Brassica rapa)}

tanaman akan secara merata pada setiap bagianya, sehingga proses fotosintesis pada tanaman berjalan dengan lancar dan memberikan hasil yang optimal pada fase vegetatif ( Anom, 2009 ).

Hal tersebut terbukti pada hipotesis pertama dan kedua bahwa semakin lebar jarak tanam yang digunakan maka dapat meningkatkan pertumbuhan dan hasil, dan juga dengan jarak tanam $20 \mathrm{~cm} \times 20 \mathrm{~cm}$ memberikan pertumbuhan dan produksi sawi pak choi yang optimal. Ini membuktikan bahwa penggunaan jarak tanam pada lokasi yang berbeda atau pada penelitian sebelum dengan lokasi penelitian sekarang dengan jarak tanam yang sama memberikan hasil yang optimal. jarak tanam $20 \mathrm{~cm} \times 25 \mathrm{~cm}$ memberikan pertumbuhan sawi pak choi tidak begitu optimal, karena jarak tanam semakin lebar akan memberikan ruang gulma yang memperebutkan unsur hara serta intesitas cahaya guna melakukan fotosintesis.

\section{Variabel Hasil}

Hasil analisis statistik menunjukan bahwa penggunaan jarak tanam memberikan pengaruh yang sangat nyata pada semua variabel pengamatan, (Tabel 4.3).

Tabel 4.3 Pengaruh Penggunaan Jarak Tanam Terhadap Variabel Hasil, Berat Segar Sawi Tan ${ }^{-1}$ Dan Berat Segar Sawi ha ${ }^{-1}$

\begin{tabular}{ccc}
\hline \multirow{2}{*}{ Perlakuan } & \multicolumn{2}{c}{ Variabel Hasil } \\
\cline { 2 - 3 } & ${\text { Berat Segar sawi } \operatorname{Tan}^{-1}(\mathrm{~g})}$ & ${\text { Berat Segar sawi Ton } \mathrm{Ha}^{-1}}^{-}$ \\
\hline J1 & $140.92 \mathrm{~b}$ & $281.84 \mathrm{~b}$ \\
J2 & $148.40 \mathrm{a}$ & $818.89 \mathrm{a}$ \\
J3 & $134.66 \mathrm{~b}$ & $652.94 \mathrm{~b}$ \\
J4 & $130.59 \mathrm{c}$ & $448.85 \mathrm{c}$ \\
J5 & $122.84 \mathrm{~d}$ & $370.99 \mathrm{~d}$ \\
J6 & $120.44 \mathrm{e}$ & $204.43 \mathrm{~d}$ \\
\hline BNT 5\% & 1.69 & 7.77 \\
\hline
\end{tabular}

Keterangan : angka - angka yang diikuti oleh huruf yang sama pada kolom yang sama berarti tidak beda nyata pada taraf uji BNT $5 \%$.

Perlakuan jarak tanam 10 × $10 \mathrm{~cm}(\mathrm{~J} 6) \quad$ paling rendah dibanding yang lainnya. Hal memberikan berat segar pertanaman yang ini disebabkan karena penggunaan jarak 


\section{Emilia: Pengaruh Jarak Tanam Terhadap Pertumbuhan Dan Hasil TanamanSawi Pak Choi (Brassica rapa)}

tanam $10 \times 10 \mathrm{~cm}$ relatif terlalu rapat sehingga timbulnya kompetisi antara tanaman yang satu dengan lainnya, sehingga kemampuan taman untuk menyerap unsur hara kurang maksimal. Semakin rapat jarak tanam maka akan mengurangi intensitas proses fotosintesis dikarenakan tanaman saling ternaungi (Anom, 2012). Dan perlakuan jarak tanam $20 \times 20 \mathrm{~cm}(\mathrm{~J} 2)$ memberikan hasil yang paling tinggi dari yang lainnya dengan peningkatan berat segar pertanaman $18,84 \%$, ini dikarenakan bahwa semakin lebar jarak tanam yang digunakan akan mengurangi persaingan antara tanaman dalam hal kemampuan menyerap unsur hara dan proses pencahayaan diterima pada setiap tanaman akan secara merata pada setiap bagianya, sehingga proses fotosintesis pada tanaman berjalan dengan lancar dan memberikan hasil yang optimal pada fase vegetatif (Anon, 2009). Sedangkan untuk perlakuan jarak tanam $20 \times 20 \mathrm{~cm}(\mathrm{~J} 2)$ memberiakan berat segar per ha yang paling rendah dibanding yang lainnya. Hal ini disebabkan karena penggunaan jarak tanam 20 × $20 \mathrm{~cm}$ memiliki populasi tanaman yang relatif kecil, Dan perlakuan jarak tanam 10 x $10 \mathrm{~cm}$ (J6) memberikan hasil yang paling tinggi dari yang lainnya dengan peningkatan berat segar per ha sebesar 36,20\%, ini dikarenakan banyaknya populasi tanaman yang digunakan pada ukuran luas lahan yang sama. (Anon, 2011).

Hal tersebut terbukti pada hipotesis pertama dan kedua untuk berat segar pertanaman bahwa semakin lebar jarak tanam yang digunakan maka dapat meningkatkan pertumbuhan dan hasil, dan juga dengan jarak tanam 20 x $20 \mathrm{~cm}$ memberikan pertumbuhan dan produksi sawi pak choi yang optimal. Ini membuktikan bahwa penggunaan jarak tanam pada lokasi yang berbeda atau pada penelitian sebelum dengan lokasi penelitian sekarang dengan jarak tanam yang sama 


\section{Emilia: Pengaruh Jarak Tanam Terhadap Pertumbuhan Dan Hasil TanamanSawi Pak Choi (Brassica rapa)}

memberikan hasil yang optimal. Sedangkan

untuk berat segar per ha tidak terjawab ini dikarenakan populasi tanaman pada ukuran luas lahan yang sama dengan jarak tanam 10 x $10 \mathrm{~cm}$ relatif lebih banyak dibandingkan dengan yang lainnya.

Perlakuan jarak tanam pada berat segar untuk setiap perlakuan (J6, J5, J4, J3, J1, J2) memberikan peningkatan persentase. Pada variabel berat segar pertanaman dengan jarak tanam $10 \times 10 \mathrm{~cm}$ ke $10 \times 15 \mathrm{~cm}$ dapat meningkatkan berat segar pertanaman sebesar $1,95 \%, 20 \times 10 \mathrm{~cm}$ meningkat sebesar $5,93 \%, 20 \times 15 \mathrm{~cm}$ meningkat sebesar $3.02 \%, 20 \times 25 \mathrm{~cm}$ meningkat sebesar 4,44\%, 20 x20 cm meningkat sebesar $5,04 \%$, dari $10 \times 10 \mathrm{~cm}$ ke $20 \times 20$ cm meningkat sebesar $18,84 \%$. Sedangkan pada variabel berat segar per ha dengan jarak tanam $20 \times 25 \mathrm{~cm}$ ke $20 \times 20 \mathrm{~cm}$ dapat meningkatkan berat segar per ha sebesar $24.03 \%, 20 \times 15 \mathrm{~cm}$ meningkat sebesar $17.35 \%, 20 \times 15 \mathrm{~cm}$ meningkat sebesar
$31,26 \%, 20 \times 10 \mathrm{~cm}$ meningkat sebesar $20,27 \%, 10 \times 15 \mathrm{~cm}$ meningkat sebesar $32,01 \%$, dari $20 \times 50 \mathrm{~cm} \mathrm{ke} 10 \times 10 \mathrm{~cm}$ meningkat sebesar 76,60\%. Meningkatnya persentase berat segar pertanaman, ini menunjukan bahwa semakin lebar jarak tanam yang digunakan, semakin meningkatkan hasil berat segar pertanaman pada tanaman sawi pak choi.

\section{Simpulan}

1. Pengaturan jarak tanam $20 \mathrm{~cm} \times 20 \mathrm{~cm}$ pada pertumbuhan tanaman sawi berpengaruh sangat nyata pada tinggi tanaman $(11,70 \%)$, jumlah daun $(15,09$ $\%)$, luas daun (14,37 ), berat segar per tanaman ( $12,82 \%)$, dan berat segar per ha $(19,55 \%)$

2. Penggunaan jarak tanam $20 \times 20 \mathrm{~cm}$ dari segi kualitas menunjukan bahwa tinggi tanaman meningkat $15,59 \mathrm{~cm}$, jumlah daun 9,17 helai, dan luas daun $52,28 \mathrm{~cm}^{2}$. berat segar pertanaman $148.4 \mathrm{~g}$, Berat segar per ha $370,9 \%$ 


\section{Emilia: Pengaruh Jarak Tanam Terhadap Pertumbuhan Dan Hasil TanamanSawi Pak Choi (Brassica rapa)}

\section{Ucapan Terima Kasih}

Pada kesempatan ini penulis ingin mengucapkan terima kasih kepada semua pihak yang telah membantu dengan caranya masing-masing dalam melengkapi tulisan ini.

\section{DAFTAR PAUSTAKA}

Anem M, 2011. Budidaya sawi pak choi. http://animhosnan. blogspot.com/2011/03/sawi-putih-pakchoi.html

Anon. 1991. Dasar Agronomi. Badan kerja sama Universitas Wilayah Barat, Palembang. Hal. III-65

Anon, 2008. Pengaruh Kerapatan Tanaman. http://adnanlpp.

wordpress.com/2008/02/05/pengaruhkerapatan-tanam/

Anon, 2009. Budidaya sawi Pak Choi. http://green.kompasiana. com/penghijauan/2009/02/12/belajarmenanam-sawi-hijau-532961.html

Anon, 2010. Menanam Sawi Pak Choi. http://www.tanamsendiri. com/2010/09/menanam-sawi-pak-choi.html

Dinas Pertanian Tanaman Pangan Kab Ende. 2010-2011. Laporan Tahunan. Dinas Pertanian.

Hidayah. 2007 Pengaruh jarak tanam sawi pakchoi dan caisim http://jaraktanam.com/page/43457/jarak tanam.html

Haryanto. 2003. Budidaya Tanaman Pakchoi Di

Dataran

Tinggi. http://budidayatanamanpakchoi.com/pa ge/12767/budidaya.htl

Haryanto., 2001', Persaingan cahaya tanaman sawi. com/penghijauan/2001/02/12/belajarmenanam-sawi-hijau-532961.html

Mimbar.S.M. 1990. Pengaruh Jarak Tanam, Jumlah Tanaman/ rumpun, Kerapatan

Margianto Derajat Kemasaman Tanaman sawi, selada, logspot.com/2011/03/kemasaman tanaman . html

Rieuwpassa J Alexander, 2011. Teknik Budidaya Sawi Pak Choi. http://maluku.litbang.deptan.go.id/ind/index .php?option=com_content \& view=article\&i $\mathrm{d}=289$ :te..

Rukmono. 2005., Pengaruh Jarak TanamTerhadap Pertumbuhan dan Produksi Sawi Putih.

Rukmono. 2009., Pengaruh Jarak Tanam, Pertumbuhan dan Produksi Sawi sawian Indonesia

Rukmana. R (2009). Bertanam SawiPakchoi \& Selada, http://pakchoidanselada.com/page/1276 7/jaraktanam.html

Rukmana 2009. Taksonomi tanaman sawi wordpress.com/2000/02/05/taksonomi tanaman sawi /

Purwati. 2011. Pengaruh jarak tanam sawi pakchoi http://pengaruhjaraktanampakcho.com/p age/43587/jaraktanam.html

Junita. Manfaat Radiasi surya bagi tanaman sawi pakcoi. htt:// radiasi suria.page. html

Wahyudi. 2010 syarat tumbuh tanaman sawi pakchoi. Usaha tani. Bandung ITB 